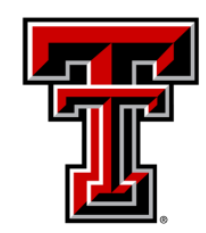

TEXAS TECH UNIVERSITY

Libraries"

\title{
EMPIRICAL SUPPORT FOR THE MEDIA PARTICIPATION HYPOTHESIS: TRENDS ACROSS PRESIDENTIAL ELECTIONS, 1992-2012
}

\section{The Texas Tech community has made this publication openly available. Please share how this access benefits you. Your story matters to us.}

\begin{tabular}{|l|l|}
\hline Citation & $\begin{array}{l}\text { Bucy, E. P., \& Groshek, J. (2018). Empirical support for the media } \\
\text { participation hypothesis: Trends across presidential elections, 1992- } \\
\text { 2012. New Media \& Society, 20(5), 1889-1909. } \\
\text { https://doi.org/10.1177/1461444817709281 }\end{array}$ \\
\hline Citable Link & $\underline{\text { https://hdl.handle.net/2346/85179 }}$ \\
\hline Terms of Use & $\underline{\text { CC BY-NC }}$ \\
\hline
\end{tabular}


Empirical support for the media participation hypothesis: Trends across presidential elections, | 992-20 I 2
2018, Vol. 20(5) 1889-1909

(C) The Author(s) 2017

Reprints and permissions: sagepub.co.uk/journalsPermissions.nav DOI: | 0.1 |77/|46|4448|770928| journals.sagepub.com/home/nms

\title{
Erik P Bucy
}

Texas Tech University, USA

\section{Jacob Groshek}

Boston University, USA

\begin{abstract}
This study empirically examines the media participation hypothesis advanced by Bucy, analyzing the influence of traditional and participatory media use across six US presidential elections. Multivariate analyses of American National Elections Study data demonstrate that as participatory media become more prevalent and utilized in an electoral system, corresponding and statistically significant increases in political system efficacy - the perception of governmental responsiveness - can be observed among the heaviest users of participatory media. Enhanced engagement with interactive media in combination with traditional media also translates into more positive assessments of democratic processes than use of traditional media alone. At the same time, increased engagement with participatory media shows a weak and negative association with political trust. Findings for the study uphold the basic tenets of the hypothesis, suggesting the framework provides a useful lens for understanding the tightening relationship between citizenship, use of communication technology, and democratic processes.
\end{abstract}

\section{Keywords}

Interactive media, media participation, perceived governmental responsiveness, political interactivity, political system efficacy, political trust

\section{Corresponding author:}

Erik P Bucy, College of Media and Communication, Texas Tech University, Box 43082, Lubbock,

TX 79409-3082, USA.

Email: erik.bucy@ttu.edu 
Despite their tendency to amplify troublesome trends, including media fragmentation, political polarization, and, in the most recent election cycle, the dissemination of rampant insults, wild accusations, and fake news, digital communication technologies and the interactivity they afford retain the capacity to foster a perception of the public sphere as an open, accessible, and ultimately responsive space. This perception seems to be cultivated by the ability of interactive media users to find and create content, "talk back" to other users, support campaigns and causes, spout opinions, and partake in various forms of political action, all with relative ease (Dahlgren, 2009). Notwithstanding broader arguments about whether such forms of media participation constitute a thick or thin form of citizenship, interactive platforms and formats facilitate the democratic promise of ongoing engagement in public affairs, encapsulated by the elementary idea that in order to feel like citizens, people must first be able to act like citizens (Bucy and Gregson, 2001).

When this shift to mediatized forms of involvement began to occur en masse, Bucy (2005) predicted that increased use of participatory media for political purposes would, over time, return a sense of agency to citizens and engender a perception of symbolic empowerment that psychological proximity to the political process affords. As political campaigns become increasingly conducted through social media and other digital communication platforms, and candidates and office holders feel increasingly comfortable speaking directly to constituents through their social media accounts, the distinction between offline and online participation is rapidly fading. Indeed, media participation through networked architectures affords citizens with continuous opportunities for civic engagement that traditional media has historically resisted.

Considerable debate exists about the nature of these network effects (see Boulianne, 2009; Hindman, 2009; Margolis and Resnick, 2000). The argument here is that rather than focusing on system-level outcomes, such as policy changes, the relative influence of parties in electoral politics, or shifts in governmental expenditures, mediated forms of involvement have the potential to foster perceptions of responsiveness at the individual level, which should produce positive assessments of the public sphere. Operationally, this sense of responsiveness can be measured in terms of outcomes like system efficacy and political trust - and tracked in public opinion surveys. Formalized as a longitudinal prediction, the media participation hypothesis specifically holds that

as political involvement becomes increasingly reliant on new media formats and technologies, intensive use of interactive public affairs media will produce a heightened sense of system satisfaction and political efficacy, a trend that should manifest itself longitudinally as mass media become more interactive in nature. (Bucy, 2005: 110)

Departing from conventional notions of political activity, which privilege in-person assembly and downplay the participatory opportunities inherent in communication technology - a view consistent with hierarchical models of civic life where media use is considered the most common but least significant mode of political activity (e.g. Milbrath, 1965) - media participation recognizes a larger, over-time benefit from interstitial involvement in public affairs that technology affords. By providing a "space for citizens to debate politics and express their support for, or discontent with, policies or a 
particular office holder without requiring any material response from the political system" (Bucy and Gregson, 2001: 377-378) media participation offers the perception of access and the possibility of peer recognition.

The idea that increased engagement with interactive media will have positive effects on political attitudes and perceptions has found considerable support in recent years (see, for example, Boulianne, 2009; Gil de Zúñiga et al., 2009; Xenos and Moy, 2007). But with a few notable exceptions from true panel designs around election cycles (e.g. Dimitrova et al., 2014; Gil de Zúñiga et al., 2014; Shah et al., 2005), most studies examining this proposition have been conducted with cross-sectional data from single points in time. Missing from this mounting body of evidence is an analysis that empirically assesses the effects of media participation from the inception of interactive formats in politics to the contemporary moment. Until recently, not enough time or data had amassed to perform a meaningful over-time analysis of the media participation hypothesis. Now, two decades into the idea of an "electronic republic" (Grossman, 1995), the data exist to observe long-term trends in the electorate.

The study reported here empirically tests the media participation hypothesis in the context of six presidential elections. To map over-time relationships, we model American National Election Studies (ANES) data across a 20-year timespan and perform regression analysis on election data from 1992 to 2012. For our measure of participatory media engagement, we construct a blended media use variable that combines different forms of political news consumption and compare it against conventional news use (newspapers and television) over a two-decade timeframe. As expected, engagement with participatory media for political news and information increases significantly over time and parallels the rise of new media formats. Next, we test our blended media use variable in models predicting relationships with political system efficacy and trust in government over time. Findings suggest that engagement with participatory media has consistent, positive effects on perceptions of political system efficacy but a weak, negative influence on political trust that varies by year. Although these results do not eliminate all alternative explanations for the relationships observed, they are strongly suggestive of the predicted patterns and highlight the need for further confirmatory research.

\section{Media participation}

As a prediction premised on a time horizon, the media participation hypothesis owes its lineage to the knowledge gap hypothesis (Tichenor et al., 1970), which posited uneven rates of information gain over time based on socioeconomic status (SES). In the case of media participation, political system efficacy - a responsive outlook on democracyreplaces information gain and differential forms of media use replace SES as a criterion measure. If the knowledge gap hypothesis presented itself as a "fundamental explanation for the apparent failure of mass publicity to inform the public at large" (Tichenor et al., 1970: 161), the media participation hypothesis is offered as an explanation for the apparent failure of interactive media, the Internet in particular, to radically transform politics into an idyllic virtual public sphere (see Hindman, 2009; Margolis and Resnick, 2000). Rather, with the increasing integration of interactive communication technology into the conduct of electoral politics, citizens come to feel the system is more accessible and open 
to involvement; that perception then presumably improves citizen satisfaction with political openness and evaluations of system functioning - a relationship that can be subjected to empirical analysis.

The hypothesis, which also draws inspiration from McLuhan (1964), is consistent with a media ecology or environmental view of the now encompassing and highly interconnected nature of the networked media environment (see Holbert, 2004; Newhagen and Levy, 1998). The rise of interactive media formats in the early 1990s, including online forums, talk radio, and televised townhall meetings that promoted a sense of dialog, arguably opened a political system that, dominated by negative advertising in the decade prior, had largely relegated citizens to a passive role in the electoral process (Buchanan, 1991; Jamieson, 1992). The onset of political interactivity brought unique opportunities for both horizontal and vertical communication between citizens and candidates, reducing the perceived distance between voters and elites - a trend that continues today through social media platforms and overtures campaigns make to voters during elections to provide a semblance of enhanced dialog and responsiveness (see Stromer-Galley, 2014; Sundar and Bellur, 2011). ${ }^{1}$

Taking technology seriously entails designating a role for mediated involvement that goes beyond simply providing a communication platform for conventional politics, a place that traditional media have long occupied (Graber and Dunaway, 2015). Questions about fomenting dissent, transforming politics, or provoking revolution aside, the role that interactive media play in cultivating a sense of affective involvement and expressive engagement cannot be discounted (see Papacharissi, 2015). Indeed, in an era of social media, flattened communication hierarchies, and always-on networked devices, the perceived distance between political actors and citizens has never been smaller. Through increasingly transparent, immersive, and portable interfaces, technology reduces the psychological distance between media users and important events (Newhagen, 2012; Xie and Newhagen, 2014), a dynamic that assumes added salience in heavily mediated contexts like major breaking news stories and heated election campaigns.

Besides reduced distance, the cumulative effects of time need to be explicitly considered in technology studies (see Lee and Whitley, 2002), in the present case to demonstrate the subtle but important sociotechnical changes on citizens' perceptions of and engagement with the political process over multiple election cycles. Just as once-separate industries, namely, broadcasting, computing, and telecommunications, have converged into overlapping market sectors (Negroponte, 1995), so have media, politics, and citizenship become more coincident and structurally inseparable in recent decades (Iyengar, 2015). These trends are illustrated by the Venn diagrams in Figure 1.

The significance of this overlapping trajectory is twofold. First, political convergence brings citizens and elites into closer proximity. Elites can now hear more frequently and easily from constituents (or monitor the opinion environment), if they care to listen, and citizens can engage in more democratically consequential actions with fewer barriers to participation than was previously the case (see Bimber, 2003; Coleman and Blumler, 2009). Second, as the media system becomes increasingly intertwined with the political system, media participation provides citizens with far more opportunities to perform their role as citizens than traditional configurations have allowed, providing the ongoing, interstitial involvement in politics that participatory democracy requires (Bucy and Gregson, 2001). ${ }^{2}$ 


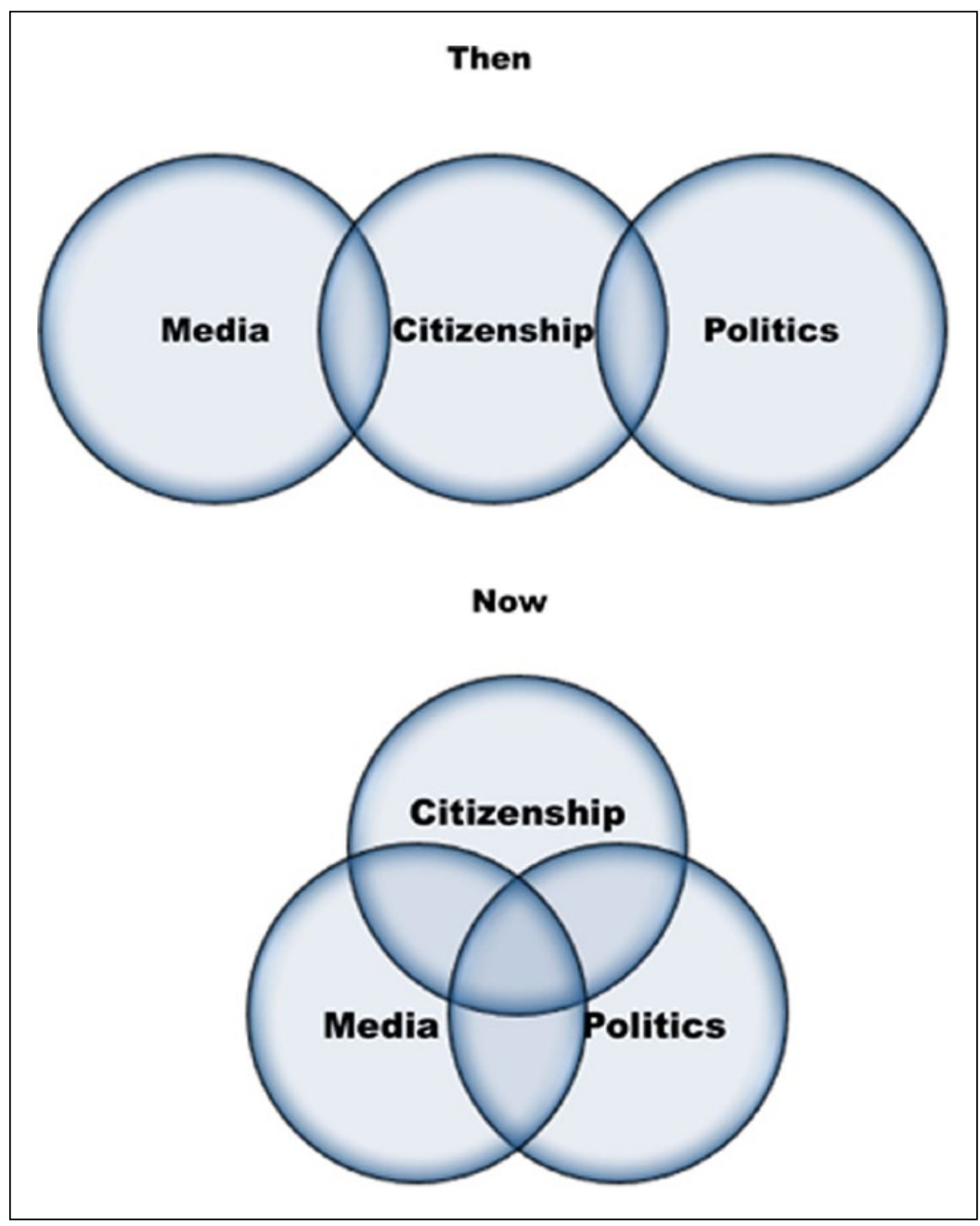

Figure I. Illustration of the increasingly overlapping nature of media, citizenship, and politics.

The present study provides the first empirical examination of the hypothesis by documenting the association of participatory media use with political outcomes over time. The results shed new light on the considerable social shift towards interactive communication that has taken place over the past 20 years but has yet to be examined from a perceptual standpoint, particularly for its temporal contours. Although the ANES data we rely on for evidence are cross-sectional in nature, a function of the availability of publicly accessible datasets that measure many variables across time, they have the advantage of national representativeness, question consistency, in-person data collection, and coincidence with presidential elections. ${ }^{3}$

When considering the civic and psychological rewards that may result from intensive interactive media use, such as peer recognition and a sense of enhanced voice 
(Bucy and Gregson, 2001), the media participation perspective suggests that positive spillover effects will occur. Namely, the sense of enhanced involvement and recognized civic agency that media participation engenders should produce improved perceptions of the political environment's responsiveness, particularly among interactive media users. As more forms of participatory media become integral with news coverage of elections, and campaigns themselves provide increasing (though carefully managed) opportunities for political interactivity (Stromer-Galley, 2014), this sense of political system efficacy should show a positive relationship with interactive media use in public opinion measures.

Important to note, however, is that an enhanced feeling of responsiveness does not guarantee a rosy assessment of politics and governance-the rancor of campaigns, uncivil tenor of partisan discourse, and continually contested news coverage of politics can affect citizen attitudes in a negative direction (Cappella and Jamieson, 1997; Moy and Hussain, 2011), even if the political system is regarded as more accessible. While actively "engaging in the democratic process can enhance feelings of political trust and efficacy" (Moy and Hussain, 2011: 221), the increasing volume of political negativity rising with political blogs, social media, talk radio, and cable news analysis programs (Sobieraj and Berry, 2011; see also Mutz and Reeves, 2005) could just as easily have a negative impact on political trust. Thus, we would expect to see differences in political evaluations vary in accordance with citizens' media repertoires - the extent to which they are utilizing a combination of interactive and traditional media or either form of media on its own.

\section{Measurement issues}

Traditionally, the influence of different forms of print and broadcast media have been considered independently and compared for their influence on political knowledge, interests, and attitudes (Chaffee et al., 1994; Drew and Weaver, 2006). More recently, media analyses have downplayed the importance of distribution channel and distinguished between "hard news" use and softer content genres (see McCombs et al., 2011). And rightfully so. With the integration of traditional media channels into an expanding array of platforms, online destinations, and mobile devices, cross-platform and complementary media use often results in media saturation — where traditional and digital media are aggregated - rather than displacement, where one medium is substituted for another (Newell et al., 2008). In situations of media saturation, we would expect to see complementary use of both legacy and new media formats, where not just the quantity but the participatory quality of media use intensifies. ${ }^{4}$

As individuals move to converged media environments where platform distinctions become more fluid (Deuze, 2011; Moore, 2010) and where a multiscreen culture now prevails, an interactivity affordances perspective (see Bucy and Affe, 2006; StromerGalley, 2014; Sundar and Bellur, 2011) better fits the commonalities between distribution channels than conventional categorizations. We therefore amend the amorphous and sometimes unproductive categorization scheme of "traditional" versus "new" media. Instead of identifying political news consumption based solely on delivery platform (e.g. newspaper, television, radio, and online), media formats are conceptually defined and 
operationalized on the basis of their potential for audience participation, that is, their capacity for reciprocal communication and involvement (see Dylko and McCluskey, 2012; Sundar and Bellur, 2011). Citizens have been participating with media in some manner for centuries (see Hamilton, 2003), yet interactive communication technologies and formats have only recently evolved to the extent where certain user-generated media now require audience interaction for viability and content (Bruns, 2009).

Differentiating media for their participatory qualities provides a more useful point of demarcation between communication channels than conventional distinctions, accounting for the unique experience of networked media use. Within this framework, certain types of media from within the typical conceptualization of broadcasting and cable, such as call-in television programs or political talk radio, are grouped with more interactive media available online (Bucy and Gregson, 2001). On the other hand, less participatory media, such as television news and newspapers, are considered noninteractive for the purposes of this analysis because the opportunities for the audience to engage beyond simple reception is structurally constrained and generally asynchronous. Likewise, these formats reduce the possibility for users to see that other citizens are simultaneously involved in political discussion and content generation, severely restricting or constraining horizontal communication between members of the media audience.

Thus, the concept of media participation provides an integrative framework consistent with an interactivity affordances approach that can extend understandings of media use that transcends delivery platforms and recognizes new hybrid forms of political engagement that are simultaneously both mass and interpersonal (Chadwick, 2013). This framework also moves beyond the general finding of Internet use as a predictor of citizen engagement in politics without consideration of engagement with multiple media formats and combined media use (Drew and Weaver, 2006; Groshek, 2011). Assessing the consequences of hybrid forms of political media engagement should offer more robust appraisals of democratic life.

\section{Quality of networked media involvement}

In any mediated interaction, observable behaviors that take place - and which subsequently influence subjective evaluations - are motivated both by the characteristics of individual users and the features of the technology that make a given set of actions possible (Sundar and Bellur, 2011). In networked environments, there are at least three categories of attributes that bear on participatory media influence: relevant content, interactive features, and information accessibility (see Bucy and Affe, 2006). During election campaigns, demand for politically relevant content increases and major media organizations dedicate special resources to political coverage, offering a rich array of multimedia offerings and news features. At the same time, campaigns utilize digital communication technologies to target and mobilize voters, raise money, and respond to opponents but operate for the most part with a "decidedly undemocratic view of controlled interactivity" (Stromer-Galley, 2014).

Given the consistent finding in the political socialization literature that engaging in civic activity is positively related to an improved political outlook, we expect that participatory media use will have a positive effect on citizen attitudes and perceptions at the 
system level, as predicted by the hypothesis. Not everything that happens online or over the airwaves is civically virtuous, however. Indeed, because of their frequently narrowcast quality, interactive media (including online news sites and talk radio) can act as a hothouse of partisan rancor and minority party discontent, fomenting distrust and casting suspicion on the motives and policies of the current administration or incumbent nominee. We would therefore expect political trust to be affected differently by participatory media use than broader perceptions about system efficacy.

Based on the foregoing theoretical justification and observations about the shifting media landscape, we take as our starting point the research expectation that, since the introduction of interactive media into the political landscape in the early 1990s, the use of participatory media formats by citizens will increase with each passing election cycle.

As these mediated behaviors become increasingly consequential, serving to publicize, organize, fund - and even fuel — campaigns, their perceived value should become more apparent, and their complementarity to established modes of offline participation more obvious. Indeed, beyond any quantitative increase in the availability of information or access to political elites through new communication configurations, participatory media qualitatively change the ways citizens engage with news, express or share political opinions, and take civic and political actions. To test the hypothesis, we compare the impact of traditional, participatory, and combined forms of news use on political system efficacy and trust in government, individual measures that capture global assessments of political functioning as well as belief or faith in political institutions. ${ }^{5}$ Specifically, we predict that

H1. Across elections, engagement with participatory media will be more positively associated with political system efficacy (H1a) and trust in government (H1b) than use of traditional media alone.

Of course, a considerable amount of research has highlighted the importance of traditional forms of media use, demographic characteristics, and partisan factors as important explanatory predictors of political attitudes and behaviors (Chaffee et al., 1994; Drew and Weaver, 2006; Iyengar, 2015; McCombs et al., 2011). To make a convincing case for media participation, the hypothesis should hold up even under a daunting set of controls. Not only should the relationships persist after other explanations are accounted for, they should show directional effects over time. It is therefore predicted that

H2. Over time, engagement with participatory media will be positively associated with political system efficacy ( $\mathrm{H} 2 \mathrm{a})$ but show a negative association with trust in government (H2b).

\section{Method}

To test these hypotheses, we analyzed ANES data for the years $1992(n=2485), 1996$ $(n=1714), 2000(n=1807), 2004(n=1212), 2008(n=2322)$, and $2012(n=5914)$ for a total sample size of 15,454 respondents. Collected over a two-decade period, these samples allow for a reasonable test of hypotheses posed since the data track the introduction 
of interactive media into presidential campaigning and reflect a steady upward trend in use and prominence (Pew Research Center, 2010). By taking as our starting point an election year (1992) that predates the widespread diffusion of the World Wide Web, a critical baseline of political efficacy and trust before widespread participatory media use in political campaigns can be established.

Survey respondents for the ANES were US citizens 18 years or older on or before the corresponding Election Day for each year. Over the years, data collection techniques have varied slightly but respondents are selected using a multistage area probability sampling technique that has come to also include online-based data collection. Using the common standard applied by the American Association for Public Opinion Research (AAPOR), the response rates for the years in question were as follows: $74.0 \%$ in 1992, $59.8 \%$ in $1996,60.5 \%$ in $2000,66.1 \%$ in $2004,63.7 \%$ in 2008 , and $38.0 \%$ in 2012 .

\section{Dependent variables}

Over the years, ANES has developed some widely used baseline indices of citizen attitudes. For the purposes of this study, two key dependent variables - political system efficacy and governmental trust - are based on the ANES multidimensional indexes, which are calculated to a uniform 0-100 scale to form even, cross-time comparisons. Details on these constructs follow.

Political system efficacy. A measure of perceived system responsiveness, ${ }^{6}$ political system efficacy combines two questions from the ANES Guide to Public Opinion and Electoral Behavior: "Do government officials care what people like you think?" and "Do people like you have any say in what the government does?" The scale mean across all years was 43.92 (standard deviation $[S D]=36.41$ ). Over time, the mean trend in system efficacy fluctuated, and declined substantially. Starting in 1992, the mean was 51.57 $(S D=40.27)$. It then dropped to $38.30(S D=37.53)$ in 1996 but rose again in 2000 to $48.16(S D=40.37)$, before declining slightly to $47.56(S D=39.82)$ in 2004 . It dropped again in 2008 , to $37.97(S D=37.83)$, and rose slightly to $39.99(S D=25.89)$ in 2012 .

Trust in government. Our second dependent variable is trust in government. The items composing the trust measure entail agreement with a series of four statements measured at the ordinal and nominal level: (1) trust in the federal government to do the right thing, (2) the federal government is run by few interests or for the benefit of all, (3) perceived amount of wasted tax money, and (4) whether government officials are thought of as crooked. On the 100-point ANES scale, trust had a substantially lower mean value than political system efficacy across all years analyzed $(M=28.86, S D=22.11)$. Though low, trust levels were observed to increase from 1992 to 2004, then dropped somewhat precipitously in 2008 and 2012. During the 1992 election, trust in government averaged $28.48(S D=20.89)$ and increased in 1996 to $31.55(S D=21.6)$. Trust again rose in 2000 to $35.98(S D=22.69)$, peaking with an incremental increase in 2004 to $36.84(S D=22.14)$, before dropping dramatically in 2008, to $26.34(S D=23.71)$. Trust in government reached its lowest point, $22.35(S D=19.17)$, in the last year of our analysis, 2012 . 
Table I. Independent variable construction—ranking and frequency of participatory and traditional media use for political news and information across all samples.

\begin{tabular}{llc}
\hline Category ranking & Media mix & Number of users \\
\hline 1 & I traditional medium used & $3037(23.0 \%)$ \\
2 & 2 traditional media used & $2018(15.2 \%)$ \\
3 & I participatory medium used & $494(3.7 \%)$ \\
4 & I participatory + I traditional media used & $2336(17.6 \%)$ \\
5 & I participatory + 2 traditional media used & $2736(20.7 \%)$ \\
6 & 2 participatory media used & $141(1.1 \%)$ \\
7 & 2 participatory + I traditional media used & $923(7.0 \%)$ \\
8 & 2 participatory + 2 traditional media used & $1548(11.7 \%)$ \\
\hline
\end{tabular}

\section{Independent variables}

The key independent variables in this study include media use measures capturing engagement with different media platforms and exposure to political news and information. Our participatory media use measure consisted of the only two items to be asked consistently across all election years considered: listening to political talk radio shows and accessing political information online. Reading newspapers and watching television news comprised our traditional media use measures. In constructing these variables, binary (yes or no) exposure conditions were added together to create indices of participatory and traditional media use.

Slightly different measures of baseline media use were created for hypothesis testing. First, the number and type of media use reported by respondents was combined into an 8-point ordinal scale $(M=4.07, S D=2.46)$. Respondents who reported using only one form of traditional media (either newspaper or television news) were assigned a value of 1 , those reporting both newspaper and television news exposure were assigned a value of 2 , and respondents who only reported use of either online news or talk radio for their campaign news were assigned a media use value of 3. Moving up the scale, respondents reporting use of one form of traditional media (either newspaper or television news), along with one form of participatory media (either talk radio or online news), were assigned a 4 on the media use scale. Reporting use of one participatory medium (either talk radio or online news) in conjunction with newspaper and television news merited a value of 5 , whereas using both forms of participatory media and no traditional media garnered a value of 6 . Heavier participatory media users, included those reporting both talk radio and online campaign information sources with at least one form of traditional media, were assigned a value of 7 , while those heavy participatory media users who also reported both newspaper and television exposure were assigned a media use value of 8 (see Table 1).

While our categories of media use provide an ordinal and not interval ranking, it progressively captures use of both participatory and traditional media engagement, and identifies those who combine or blend different forms of political news use in each election year. Bivariate correlations show that our blended media use variable was weakly 
associated with demographic factors, namely, being male (Pearson's $r=.11, p<.001)$ and having more education $(r=.25, p<.001)$. Other characteristics, including age and Republican Party identification, were not statistically significant, whereas being a Democrat $(r=-.03, p<.001)$ and more strongly partisan $(r=-.02, p<.001)$ were significantly but weakly correlated with increases in blended media use.

Admittedly, this scale does not take into account frequency of use, nor the exact nature of political media content consumed (a problem noted in the literature; see Bimber, 2001), but it does reflect the variability of different modes of media engagement and extent to which participatory and traditional media use complement one another. Table 1 showing the rankings and frequencies of our media use categories across all election years reveals that $38.2 \%$ of the sample consists of users of traditional media onlyrespondents who either read newspapers, watched television news, or both, but did not combine their traditional media use with any other platform (categories $1+2$ ). By contrast, just $4.8 \%$ of the sample consists of users of participatory media-talk radio, online sources, or both - for political news (categories $3+6$ ). The remaining $57 \%$, as described below, use varying combinations of participatory and traditional media. The low level of participatory only media use led to the conclusion that it was not realistic to analyze participatory media in isolation; therefore, blended use categories were utilized for hypothesis testing.

\section{Analysis strategy}

For Hypothesis 1, two separate factorial analysis of variance (ANOVA) models were run with election year and a collapsed, four-level version of our media use variable as the independent factors. The four media configurations tested in these models were as follows: traditional only (categories $1+2)$, participatory only $(3+6)$, light blended media use $(4+5)$, and heavy blended use $(7+8)$. The "light blended" cate-gory-respondents who used talk radio or online news in combination with newspapers or television newsconsisted of $38.3 \%$ of the sample, whereas the "heavy blended" category-respondents who used both forms of participatory media and at least one form of traditional mediaconsisted of $18.7 \%$ of the sample. Jointly, these four groups form a typology of differential media use for comparing how engagement with participatory media - alone and blended — can influence assessments of the political sphere.

For the second hypothesis, a pair of ordinary least squares (OLS) regressions were run using political system efficacy and trust as the dependent variables and our 8-level media use index as the primary independent variable. Fixed effects models were utilized to control for unobserved variances that differed across time. To contextualize media use amid other influences on political system efficacy and trust, a number of controls identified in previous research were included in these models (see Tolbert and McNeal, 2003; Xenos and Moy, 2007). Control variables included age $(M=47.11, S D=3.37)$, gender (53.9\% female), education $(M=2.78$ [high school graduate or equivalent], $S D=0.93)$, political party identification (47.2\% Democrat, $31.2 \%$ Republican), and voting (67.7\% reported having voted in the last election). Strength of partisan identification, measured on a 4-point ordinal scale $(M=2.53, S D=1.05)$, was also included as a control. 
This approach facilitated parsimonious analysis of the data across election years, including identification of other influences that may have contributed to changes in system efficacy and political trust. In addition, to account for endogeneity between the dependent variables in our regression models, both system efficacy and political trust were included as controls in models in which they were not an outcome of interest (Iyengar and Vavreck, 2012). ${ }^{7}$ In addition, separate OLS regression models were run for each election year and independent variable to specifically examine relationships within individual election years.

\section{Results}

As a general expectation, we anticipated that engagement with participatory media for political news would increase over each election cycle from 1992 to 2012. Examining this expectation with ANOVA, blended media use showed a general and sustained increase over time, from an average of $2.77(S D=1.9)$ on our 8-level index in 1992 to $3.15(S D=2.13)$ in 1996 , further jumping to $3.69(S D=2.48)$ during the 2000 election. Blended media use continued to climb upward in 2004, rising to a mean score of 4.55 $(S D=2.59)$ in 2004 , then to $4.66(S D=2.46)$ in 2008 before plateauing in 2012 at 4.67 $(S D=2.40)$. While our media use variable captures both traditional and participatory news use, the rising mean value clearly indicates that use of participatory media for political information has steadily increased over time; therefore, a foundational assumption of the media participation hypothesis - that political involvement will become increasingly reliant on new media formats and technologies over time, as mass media become more interactive in nature-is confirmed.

Hypothesis 1 predicted that, across election years, engagement with participatory media (including blended news use) would be more positively associated with political system efficacy and trust in government than use of traditional media alone. The first sub-hypothesis, H1a, examined the relationship between media use (parsed here as traditional only, participatory only, light blended, and heavy blended use) and political system efficacy over time. A factorial ANOVA between election year and media use revealed a statistically significant interaction, $F(14,9304)=2.86, p=.001$, partial $\eta_{\mathrm{p}}{ }^{2}=.004$, observed power $=.996$. The estimated marginal means in Figure 2 illustrate the variation in political system efficacy over time. In addition, a statistically significant main effect of media use, $F(3,9304)=29.90, p=.001$, partial $\eta_{\mathrm{p}}{ }^{2}=.011$, observed power $=1.00$, was observed where those individuals with heavy blended media use showed the highest levels of political system efficacy across all years, even as that range fluctuated from election to election (peaking in 2000).

Hypothesis $1 \mathrm{~b}$ likewise measured how trust in government varied over elections as differentiated by varying levels of media use. The interaction for election year and media use was not significant, and the relationships between blended media use and trust in government curvilinear. Political trust peaks between 2000 and 2004 then plunges in 2008 and 2012. Neither the main effect for media use, $F(3,10,090)=0.16, p=.925$, partial $\eta_{\mathrm{p}}{ }^{2}=.000$, observed power $=.079$, nor the interaction between election year and media use, $F(14,10,090)=1.40, p=.144$, partial $\eta_{\mathrm{p}}{ }^{2}=.002$, observed power $=.832$, was significant. Considered together, these findings fail to support the prediction that 


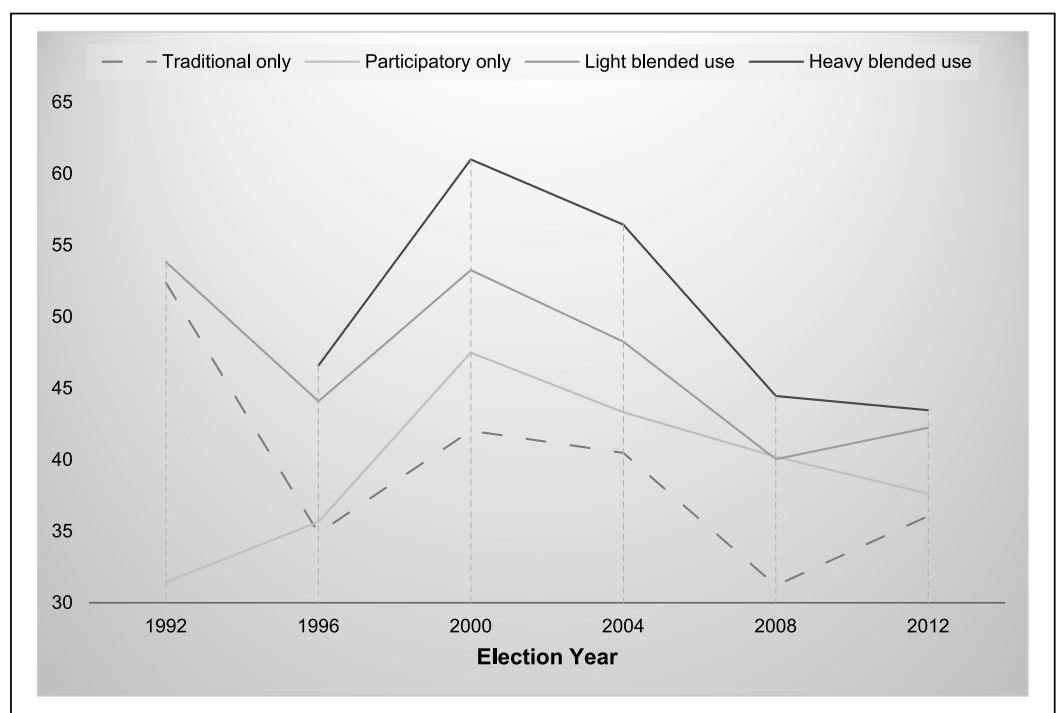

Figure 2. Estimated marginal means for political system efficacy by media use over time. The "heavy blended" category is absent for 1992 since the Internet was not available to the general public at that time and no question was posed by ANES to citizens.

engaging with more participatory forms of media would be associated with increased trust in government, although that pattern was evident from 1996 to 2000. The estimated marginal means plots in Figure 3 illustrate the relationship between media use and trust in government over time.

Hypothesis 2 predicted that engagement with participatory media will be positively associated with political system efficacy but show a negative association with trust in government. A pair of time fixed-effects linear OLS regression models were used to examine this hypothesis for political system efficacy and trust, while taking into account election-specific conditions that may have varied with each election cycle.

Political system efficacy was modeled to test H2a. Here, increased blended media use remained a statistically significant predictor, even while controlling for numerous social, political, demographic, and election-related factors. Specifically, engagement with participatory media through our blended media use measure positively predicted political system efficacy, $B=0.892, S E=0.189, p=.001$. The hypothesis was thus supported. A number of control variables, including election year $(1992,2000,2004,2012)$, age, education, party affiliation (identifying as a Republican), strength of partisanship, offline political participation, having voted, and trust in government were significant as wellnot a surprising result, given the large sample sizes. These relationships are summarized in Table 2.

In contrast with the findings for political system efficacy, the results for political trust did not completely support the expectations in Hypothesis $2 \mathrm{~b}$. There was only weak support for the prediction that engagement with participatory media would be negatively related to trust in government. Although a negative relationship was observed, the 


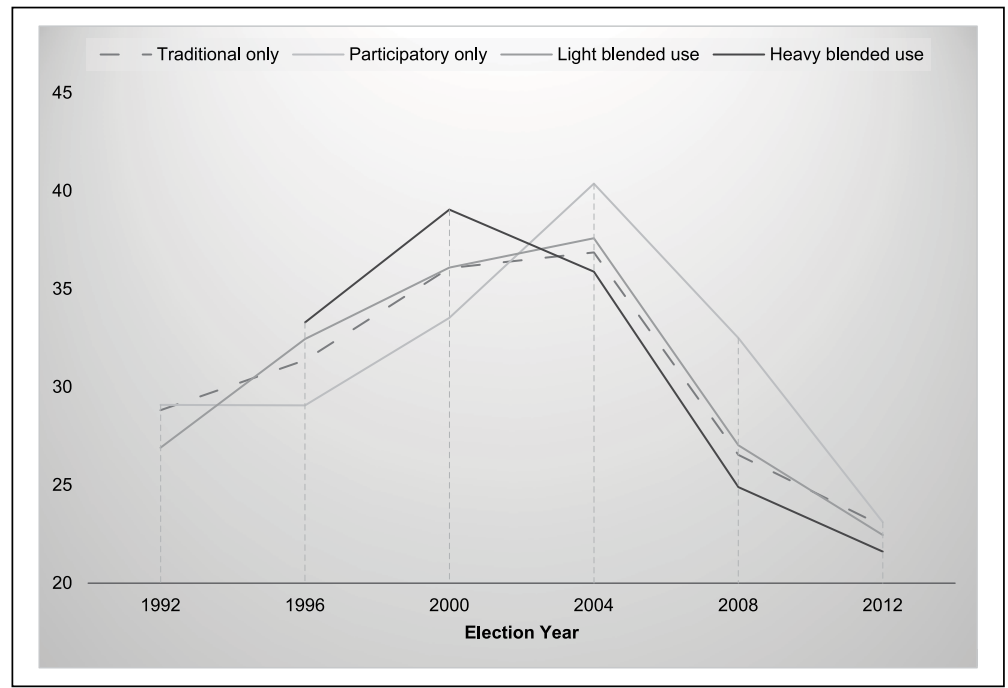

Figure 3. Estimated marginal means for trust in government by media use over time.

The "heavy blended" category is absent for 1992 since the Internet was not available to the general public at that time and no question was posed by ANES to citizens.

Table 2. Fixed effects regression analyses for political system efficacy and trust in government.

\begin{tabular}{|c|c|c|c|c|}
\hline \multirow[t]{2}{*}{ Variables } & \multicolumn{2}{|c|}{ Political system efficacy } & \multicolumn{2}{|c|}{ Trust in government } \\
\hline & $B$ & $(S E)$ & $B$ & $(S E)$ \\
\hline 1992 & 17.67 & $(1.22)^{* * * *}$ & -6.32 & $(0.73)^{* * *}$ \\
\hline 2000 & 7.36 & $(\mathrm{I} .3 \mathrm{I})^{* * * *}$ & 3.17 & $(0.78)^{* * *}$ \\
\hline 2004 & 3.89 & $(\mathrm{I} .5 \mathrm{I})^{* *}$ & 4.52 & $(0.90)^{* * *}$ \\
\hline 2008 & 2.41 & $(\mathrm{I} .5 \mathrm{I})$ & -5.50 & $(0.90)^{* * *}$ \\
\hline 2012 & 4.59 & $(1.37)^{* * * *}$ & -8.84 & $(0.8 I)^{* * * *}$ \\
\hline Age & -0.24 & $(0.12)^{*}$ & -0.12 & $(0.07)^{\dagger}$ \\
\hline Gender (being male) & -0.93 & $(0.76)$ & 0.49 & $(0.45)$ \\
\hline Education & 7.15 & $(0.45)^{* * * *}$ & -0.58 & $(0.27)^{*}$ \\
\hline Democrat & 2.03 & $(1.31)$ & 2.99 & $(0.78)^{* * *}$ \\
\hline Republican & 2.84 & $(1.35)^{*}$ & -0.15 & $(0.81)$ \\
\hline Partisanship strength & 0.96 & $(0.45)^{*}$ & 0.63 & $(0.27)^{*}$ \\
\hline Offline political participation & 2.70 & $(0.38)^{* * * *}$ & -0.81 & $(0.23)^{* * *}$ \\
\hline Blended media use & 0.89 & $(0.19)^{* * * *}$ & -0.02 & $(0.11)^{\dagger}$ \\
\hline Voted in election & 7.41 & $(1.10)^{* * * *}$ & -2.21 & $(0.66)^{* * *}$ \\
\hline Political system efficacy & - & & 0.18 & $(0.01)^{* * *}$ \\
\hline Trust in government & 0.5 & $(0.02)^{* * * *}$ & - & \\
\hline Adjusted $R^{2}$ & 0.17 & & 0.15 & \\
\hline$N$ & 8151 & & 8151 & \\
\hline
\end{tabular}

Coefficients reported are unstandardized and were derived with fixed effects operators for time. The year 1996 was dropped to avoid perfect collinearity in time. Blended media use ranges from (I) traditional media use only to (8) all forms of media used. ${ }^{\dagger} p<.10 . * p<.05$. $* * p<.01$. $* * * p \leq .001$. 
relationship approached statistical significance, $B=-0.195, S E=0.113, p=.083$. As with the model for system efficacy, several controls were significantly associated with the dependent variable, including all election years, offline political participation, having voted, political system efficacy, education, identifying as a Democrat, and strength of partisanship (see Table 2).

Finally, additional regression models were run for each year for each dependent variable (see Table 3). Controlling again for a series of relevant variables, media participation persisted as a significant predictor of political system efficacy across all election years except 1992, and was significant and negative for trust only in 2008. In addition to the models presented, we carried out overall, year-by-year and cross-lagged correlations with both dependent variables and the 8-level blended media use measure. These procedures all produced a weak but significant positive correlation between increased media use and efficacy, and a negligible coefficient with trust that was negative and nonsignificant in some instances. We also created an interaction term by multiplying year by the media use measure and performed the same correlational analyses. This process yielded nearly identical results. In sum, the outcome of these tests reinforce and validate the findings observed in the above analyses.

Table 3. Summary table of media participation effects on political system efficacy and trust in government.

\begin{tabular}{lcccccc}
\hline & 1992 & 1996 & 2000 & 2004 & 2008 & 2012 \\
\hline Political system & -0.05 & $1.32 * * *$ & $1.18^{* * *}$ & $1.43 * *$ & $1.29 * * *$ & $0.5 I^{* *}$ \\
efficacy & $(0.45)$ & $(0.47)$ & $(0.43)$ & $(0.58)$ & $(0.49)$ & $(0.26)$ \\
Trust in & -0.20 & 0.01 & -0.08 & -0.32 & $-0.64 * *$ & -0.14 \\
government & $(0.24)$ & $(0.29)$ & $(0.26)$ & $(0.33)$ & $(0.32)$ & $(0.19)$ \\
\hline
\end{tabular}

Standard deviations in parentheses.

\section{Discussion}

Studies of participatory media and political involvement that consider multiple elections over time are uniquely situated to reveal slowly evolving trends. Now that enough time has passed for interactive media to become entrenched in social and political life, scholars of new media can increasingly embrace an approach to technology studies that builds in time as an central consideration, placing participatory media formats on a trajectory of historical developments in audience involvement, horizontal dialog, and user-generated contributions that began decades, not years, ago. With a longer horizon, trends not observable at a single point in time can come into clearer view. In this study, we have mapped fluctuations in citizen evaluations across changing political conditions to show the persistent associations that participatory media use have with perceptions of system responsiveness - a relationship that endures even amid a rigorous set of controls.

Our analysis documents that engagement with participatory media formats for political information and dialog has increased in each presidential election cycle between 1992 and 2012. Correspondingly, use of nonparticipatory, or traditional, media alone has declined over time. While this point has been made elsewhere with regard to general 
news consumption (see Pew Research Center, 2010), our study is one of the first to specifically track this trend in terms of political media uses. In addition, findings here highlight the complementary nature of participatory and traditional media use, bolstering the case for media coexistence and saturation. Even as participatory media become highly integrated into the political ecology, they do not completely eclipse all other forms of conventional media use - at least by the measures employed here. Follow-up research should take a much closer look at the burst of social media reliance for political news over the past two election cycles and examine these questions in terms of the unique affordances of individual platforms.

With respect to the media participation hypothesis, we found support for several foundational premises. First, engagement with both traditional and participatory media use across elections was shown to be more strongly related to political system efficacy than use of traditional media alone. Once interactive media achieved a toehold in presidential elections (c. 1996), use of traditional media only was associated with the lowest levels of political system efficacy (see Figure 2). These findings reinforce the idea that engagement with participatory media improve perceptions of democratic processes - and, by extension, that mediated politics has a dynamic and open quality that interactive media facilitate. Yet, this relationship appears to be bounded by the prevailing conditions in any given election that also impact one's sense of political system efficacy and trust. Thus, rather than augmenting political evaluations in a direct linear fashion over time (notably, trust markedly decreased in 2008 and 2012), involvement with participatory media seems to influence these assessments within the general tenor of an election cycle.

The marginally significant, negative relationship between blended media use and political trust points to an important qualification. Namely, while media participation may have a salutary influence on perceptions of system level functioning (e.g. political efficacy), this same interactive engagement with political campaigns and political rhetoric can have a corrosive effect on personal attitudes (e.g. trust in government). Indeed, the participatory formats featured in this study - talk radio and the Internet for political news - are susceptible to partisanship and can, at times, become overheated venues for political discourse (see Bennett and Iyengar, 2008; Harrison and Hirst, 2007). ${ }^{8}$ The nonsignificant (and negative) findings for trust may also signal that engagement with more interactive forms of media could lead to more selective information exposure and greater levels of skepticism and cynicism (see Tsfati and Cohen, 2013), a question for future research.

The fact that greater engagement with participatory media correlated with increased political system efficacy during a period in which overall perceptions of system responsiveness declined is telling. Compared to those with lower levels of participatory media use, citizens who engaged with more participatory media, notably in conjunction with traditional media, reported higher levels of political system efficacy. Although these tendencies did not completely overcome general trends tied to each election, they are clearly indicative of a media-engrossed political experience. The findings for trust also offer an important clarification to the broader hypothesis - namely, with the fluctuating tenor of elections over time, participatory media use does not have a uniformly positive association with political evaluations. Rather, the relationship is contingent on the outcome measured and year in question.

The findings reported here further show how multiple media use is a valuable measure for understanding linkages with system-level assessments. Indeed, the most potent factors 
in this study were those that jointly considered participatory media use along with traditional media use. In what has now become a converged media environment of embedded online and offline activities, artificially isolating individuals' media repertoires into separate, discrete behaviors for analysis and comparison betrays actual practice (see Deuze, 2011). Indeed, in a convergent communication context, treating different forms of media use as meaningfully distinct forecloses on an important opportunity to identify latent relationships that are identifiable by sorting media behaviors on the basis of their participatory qualities rather than delivery platform - a perspective that recognizes interactivity as a key affordance of digital communication technology (Bucy and Affe, 2006).

Altogether, this study found meaningful support for the media participation hypothesis and extended the framework as one that gains traction with widespread Internet adoption and political application of interactive media. This pattern of influence could be observed even while taking into account the plateauing of participatory media use over the last few election cycles. As research advances, examining the correlates of media participation in a more mature and precisely defined networked environment becomes a compelling proposition. Towards this end, future research should consider a broader range of interactive formats and applications, as well as different user communities segmented by demographics or other important differences, to further test the hypothesis' contingent conditions while integrating a wider array of political phenomena as outcome measures. It remains to be determined, with more precise media use measures, further consideration of political orientations, and even qualitative responses, how media participation trends relate to other critical considerations such as political cynicism and voting.

The present analysis was limited by the cross-sectional nature of the survey data examined and standardized questions that were available. While national in scope, and drawn from random probability samples, the data paint a broad and imprecise picture of the hypothesis overall. A more detailed set of relationships can be investigated with media use questions that specify platforms used, the type of news and information consumed, the quality and nature of networked interaction, and duration of media activities performed. In this analysis, the use of the Internet for political information could have encompassed anything from campaign or government websites, to Google News or other portal pages, to personal - or partisan - blogs, to the websites of mainstream news organizations. With no way of controlling for different online sources, our measure of participatory media use was quite blunt. Future studies should, as Bimber (2001) suggests, supplement nationally standardized data collections with custom surveys to explore Internet use in much greater detail. Indeed, to show causality, panel designs or survey-experiments should be fielded so that changes in outcomes can be directly attributed to different forms of media use and engagement. Moreover, the analysis reported here can only speak to the US context. Subsequent studies should investigate the hypothesis' applicability to other political systems and national settings, comparing highly "mediatized" democracies (Strömbäck and Esser, 2009) to political systems with much tighter party control.

Based on the over-time analyses reported here, we now have some evidence that political consequences of participatory media use are contingent on parallel use of traditional media, perhaps as an informational foundation or reference point for engaged citizenship. Although they are under threat economically, vilified by partisan activists, and tainted by purveyors of "fake news," traditional media still form the "iron core" of hard 
news (Jones, 2009). As computers and other media technologies become increasingly television-like and television experiences become increasingly computer-like, the distinctions between participatory and nonparticipatory media formats will continue to diminish. Movement through the broader information ecology is increasingly becoming a lifestyle of continuous media sampling and engagement rather than a series of discrete activities that can be cleanly separated for analysis. With the proliferation of participatory media in politics, there is an opportunity using the framework introduced here to better understand the tightening relationship between citizenship, communication technology, and democracy. More precise measures with data and study designs capable of testing causal relationships in a more controlled fashion should yield a much richer set of insights into the evolving nature of citizenship and political perception.

\section{Funding}

The author(s) received no financial support for the research, authorship, and/or publication of this article.

\section{Notes}

1. Interestingly, Stromer-Galley (2014) in her over-time analysis of online campaigns qualifies the type of involvement that most presidential campaign websites offer as a type of "controlled interactivity," where the ability to talk to, let alone talk back, to the campaign or candidate is highly constrained.

2. By affording mass involvement in political life, media participation also serves the socially valuable purpose of bringing closer to reality the classical goal of full citizen participation without over-extending already burdened political institutions (Bucy and Gregson, 2001).

3. Cross-sectional studies are useful for estimating the prevalence of population characteristics and establishing association between two or more variables at a single point in time but cannot establish causal linkages in a longitudinal fashion (Levy and Lemeshow, 2008). We recognize this as a limitation of the analysis yet maintain that the data are suitable for showing relationships between key variables and demonstrating the general plausibility of the hypothesis.

4. Declines in legacy or incumbent media use tend to be slow, Newell et al. (2008: 137) note, "leading to a population that can be characterized as adopting new media quickly, and disadopting incumbent media slowly, if at all."

5. The inclusion of political trust extends beyond the media participation hypothesis' original formulation. Nevertheless, we felt it important to consider more than one outcome of interest in this empirical examination of the concept to demonstrate the framework's robustness.

6. All scale items and data can be retrieved from the American National Election Studies (ANES) Guide to Public Opinion and Electoral Behavior, available online at: http://www. electionstudies.org/nesguide/gd-index.htm

7. While it is possible to explore other measures and interaction terms in identifying such models, this is one of the first empirical inquiries into media participation as an overarching framework, so we began by looking at broad impacts and direct implications over time. Extensive multilevel models were analyzed during pretesting, including many models with interaction terms (e.g. participatory media use was interacted with political system efficacy). In some cases, output indicated that other, intermediate outcomes were significantly impacted, but there were no models that added considerable explanatory power to the key variables of interest reported in this study. 
8. This of course does not include mainstream news sites of legacy media but "digitally native" blogs, information sources, and social media platforms that are prone to hyper-partisanship and amateur opinion journalism, where "everyone can weigh in on everything" (see Goodykoontz, 2016; Sobieraj and Berry, 2011).

\section{References}

Bennett WL and Iyengar S (2008) A new era of minimal effects? The changing foundations of political communication. Journal of Communication 58(4): 707-731.

Bimber B (2001) Information and political engagement in America: the search for effects of information technology at the individual level. Political Research Quarterly 54(1): 53-67.

Bimber B (2003) Information and American Democracy: Technology in the Evolution of Political Power. New York: Cambridge University Press.

Boulianne S (2009) Does Internet use affect engagement? A meta-analysis of research. Political Communication 26(2): 193-211.

Bruns A (2009) Blogs, Wikipedia, Second Life, and Beyond: From Production to Produsage. New York: Peter Lang.

Buchanan B (1991) Electing a President: The Markle Commission Research on Campaign '88. Austin, TX: University of Texas Press.

Bucy EP (2005) The media participation hypothesis. In: McKinney MS, Kaid LL, Bystrom DG, et al. (eds) Communicating Politics: Engaging the Public in Democratic Life. New York: Peter Lang, pp. 107-122.

Bucy EP and Affe RB (2006) The contributions of net news to cyber democracy: civic affordances of major metropolitan newspaper sites. In: Li X (ed.) Internet Newspapers: Making of a Mainstream Medium. Mahwah, NJ: Lawrence Erlbaum, pp. 227-242.

Bucy EP and Gregson KS (2001) Media participation: a legitimizing mechanism of mass democracy. New Media \& Society 3(3): 359-382.

Cappella JN and Jamieson KH (1997) Spiral of Cynicism: The Press and the Public Good. New York: Oxford University Press.

Chadwick A (2013) The Hybrid Media System: Politics and Power. New York: Oxford University Press.

Chaffee SH, Zhao X and Leshner G (1994) Political knowledge and the campaign media of 1992. Communication Research 21(2): 305-324.

Coleman S and Blumler JG (2009) The Internet and Democratic Citizenship: Theory, Practice, and Policy. Cambridge: Cambridge University Press.

Dahlgren P (2009) Media and Political Engagement: Citizens, Communication and Democracy. New York: Cambridge University Press.

Deuze M (2011) Media life. Media, Culture \& Society 33(1): 137-148.

Dimitrova DV, Shehata A, Strömbäck J, et al. (2014) The effects of digital media on political knowledge and participation in election campaigns: evidence from panel data. Communication Research 41(1): 95-118.

Drew D and Weaver D (2006) Voter learning and interest in the 2004 presidential election: did the media matter? Journalism \& Mass Communication Quarterly 83(1): 25-53.

Dylko I and McCluskey M (2012) Media effects in an era of rapid technological transformation: a case of user-generated content and political participation. Communication Theory 22(3): 250-278.

Gil de Zúñiga H, Molyneux L and Zheng P (2014) Social media, political expression, and political participation: panel analysis of lagged and concurrent relationships. Journal of Communication 64(4): 612-634.

Gil de Zúñiga H, Puig-I-Abril E and Rojas H (2009) Weblogs, traditional sources online, and political participation: an assessment of how the Internet is changing the political environment. New Media \& Society 11(4): 553-574. 
Goodykoontz B (2016) Hyper-partisan sites, fake news, and the media: a fight for Facebook's audience. USA Today Network, 14 November. Available at: http://www.azcentral.com/story/ entertainment/movies/billgoodykoontz/2016/11/13/political-misinformation-spreads-duringelection/92900696/ (accessed 5 March 2017).

Graber DA and Dunaway J (2015) Mass Media and American Politics. 9th ed. Los Angeles, CA: SAGE.

Groshek J (2011) Media, instability, and democracy: examining the Granger-causal relationships of 122 countries from 1946 to 2003. Journal of Communication 61(6): 1161-1182.

Grossman LK (1995) The Electronic Republic: Reshaping American Democracy for the Information Age. New York: Viking Press.

Hamilton JW (2003) Remaking media participation in early modern England. Journalism 4(3): 293-313.

Harrison J and Hirst M (2007) Communication and New Media: From Broadcast to Narrowcast. New York: Oxford University Press.

Hindman M (2009) The Myth of Digital Democracy. Princeton, NJ: Princeton University Press.

Holbert RL (2004) An embodied approach to the study of media forms: introducing a social scientific component to medium theory. Explorations in Media Ecology 3(2): 101-120.

Iyengar S (2015) Media Politics: A Citizen's Guide. 3rd ed. New York: W. W. Norton \& Company.

Iyengar S and Vavreck L (2012) Online panels and the future of political communication research. In: Semetko HA and Scammell M (eds) The Sage Handbook of Political Communication. Thousand Oaks, CA: SAGE, pp. 225-240.

Jamieson KH (1992) Dirty Politics: Deception, Distraction, and Democracy. New York: Oxford University Press.

Jones AS (2009) Losing the News: The Future of the News that Feeds Democracy. New York: Oxford University Press.

Lee $\mathrm{H}$ and Whitley EA (2002) Time and information technology: temporal impacts on individuals, organizations, and society. Information Society 18(4): 235-240.

Levy PS and Lemeshow S (2008) Sampling of Populations: Methods and Applications. 4th ed. Hoboken, NJ: John Wiley \& Sons.

McCombs M, Holbert RL, Kiousis S, et al. (2011) The News and Public Opinion: Media Effects on Civic Life. Cambridge: Polity Press.

McLuhan M (1964) Understanding Media: The Extensions of Man. New York: McGraw-Hill.

Margolis M and Resnick DK (2000) Politics as Usual: The Cyberspace 'Revolution.' Thousand Oaks, CA: SAGE.

Milbrath LW (1965) Political Participation: How and Why Do People Get Involved in Politics? Chicago, IL: Rand McNally.

Moore MR (2010) Adaptation and new media. Adaptation 3(2): 179-192.

Moy P and Hussain MM (2011) Media influences on political trust and engagement. In: Shapiro RY and Jacobs LR (eds) The Oxford Handbook of American Public Opinion and the Media. Oxford: Oxford University Press, pp. 220-235.

Mutz DC and Reeves B (2005) The new videomalaise: effects of televised incivility on political trust. American Political Science Review 99(1): 1-15.

Negroponte N (1995) Being Digital. New York: Knopf.

Newell J, Pilotta JJ and Thomas JC (2008) Mass media displacement and saturation. International Journal on Media Management 10(4): 131-138.

Newhagen JE (2012) Hypernews, biological authenticity, and the mediation of what's important. Politics and the Life Sciences 31(1-2): 80-86. 
Newhagen JE and Levy MR (1998) The future of journalism in a distributed communication architecture. In: Borden DL and Harvey K (eds) The Electronic Grapevine: Rumor, Reputation, and Reporting in the New Online Environment. Mahwah, NJ: Lawrence Erlbaum, pp. 9-21.

Papacharissi Z (2015) Affective Publics: Sentiment, Technology, and Politics. New York: Oxford University Press.

Pew Research Center (2010) How media consumption has changed since 2000. Pew Research Center, 24 June. Available at: http://pewinternet.org/Presentations/2010/Jun/How-MediaConsumption-Has-Changed-Since-2000.aspx (accessed 5 March 2017).

Shah DV, Cho J, Eveland WP Jr., et al. (2005) Information and expression in a digital age: modeling internet effects on civic participation. Communication Research 32(5): 531-565.

Sobieraj S and Berry JM (2011) From incivility to outrage: political discourse in blogs, talk radio, and cable news. Political Communication 28(1): 19-41.

Strömbäck J and Esser F (2009) Shaping politics: mediatization and media interventionism. In: Lundby K (ed.) Mediatization: Concepts, Changes, Consequences. New York: Peter Lang, pp. 205-223.

Stromer-Galley J (2014) Presidential Campaigning in the Internet Age. New York: Oxford University Press.

Sundar SS and Bellur S (2011) Concept explication in the Internet age: the case of political interactivity. In: Bucy EP and Holbert RL (eds) Sourcebook for Political Communication: Methods, Measures, and Analytical Techniques. New York: Routledge, pp. 419-433.

Tichenor PA, Donohue GA and Olien CN (1970) Mass media flow and differential growth in knowledge. Public Opinion Quarterly 34(2): 159-170.

Tolbert CJ and McNeal RS (2003) Unraveling the effects of the Internet on political participation. Political Research Quarterly 56(2): 175-185.

Tsfati Y and Cohen J (2013) Perceptions of media and media effects: the third-person effect, trust in media, and hostile media perceptions. In: Valdivia AN and Scharrer E (eds) International Encyclopedia of Media Studies: Media Effects/Media Psychology, vol. 5. New York: WileyBlackwell, pp. 128-146.

Xenos M and Moy P (2007) Direct and differential effects of the Internet on political and civic engagement. Journal of Communication 57(4): 704-718.

Xie W and Newhagen JE (2014) The effects of communication interface proximity on user anxiety for crime alerts received on desktop, laptop, and hand-held devices. Communication Research 41(3): 375-403.

\section{Author biographies}

Erik P Bucy is the Marshall and Sharleen Formby Regents professor of Strategic Communication in the College of Media and Communication at Texas Tech University and Associate Editor of The Information Society journal. His work on new technology, political communication, and media evaluation has been published in a variety of leading journals.

Jacob Groshek is an associate professor of Emerging Media at Boston University and a founding editor of the Journal of Communication Technology. His research interests include communication technologies and their role in shaping sociopolitical change, media ethics, and studies in mobile social media and streaming television. 